\title{
A SIMULATION TECHNIQUE FOR OPTIMISING MAINTENANCE TEAMS FOR A SERVICE COMPANY
}

\author{
J.K. Visser and G. Howes ${ }^{1}$ \\ Department of Engineering Management \\ University of Pretoria, South Africa \\ krige.visser@up.ac.za
}

\begin{abstract}
The maintenance of some sophisticated and complex equipment - for example, diagnostic equipment used in hospitals - is frequently outsourced to the original equipment supplier or another maintenance service provider. Companies that own such assets can either enter into a service agreement, or they can use service providers on a call-out basis. A fundamental problem for the provider of maintenance services is to determine the optimum number of maintenance technicians or artisans. An investigation was done for a service company that provides planned and breakdown maintenance services to hospitals and clinics that use specialised medical imaging equipment. Data on the duration of maintenance tasks and traveling costs were used to obtain an input distribution for a simulation model. The model that was developed can now be used to determine the number of technicians that would optimise the service company's profit. This paper discusses the features of the simulation model, as well as some results obtained with the basic simulation model.
\end{abstract}

\section{OPSOMMING}

Die instandhouding van sommige gesofistikeerde en komplekse toerusting, soos byvoorbeeld diagnostiese toerusting wat in hospitale gebruik word, word dikwels uitgekontrakteer na die oorspronklike vervaardigers van die toerusting. Ondernemings wat sulke toerusting besit kan dan 'n diensleweringskontrak met die diensverskaffer aangaan, of gebruik maak van 'n uitroepstelsel. 'n Fundamentale probleem vir die diensverskaffer is om die optimum aantal tegnici te bepaal. 'n Ondersoek is gedoen vir 'n tipiese diensverskaffer wat beplande sowel as onbeplande instandhouding doen vir hospitale en klinieke wat gesofistikeerde optiese toerusting bedryf. Data vir die tydsduur van take sowel as reistyd is gebruik om insetverdelings te verkry vir die ontwikkeling van 'n simulasiemodel. Die model wat ontwikkel is kan gebruik word om die aantal tegnici te bepaal wat die wins vir die diensmaatskappy sal optimeer. Hierdie artikel bespreek die eienskappe van die simulasiemodel wat ontwikkel is, sowel as van die resultate wat met die basiese simulasiemodel verkry is.

\footnotetext{
1 This author was enrolled for the MBA degree at the Graduate School of Management, University of Pretoria.
} 


\section{INTRODUCTION}

A business enterprise needs to consider many internal and external factors if it is to be successful. These factors, and the processes to deal with them effectively, should be in place. This is commonly known as the business strategy, and normally consists of a plan for management to stake out a market position, conduct its operations, attract and please customers, compete successfully, and achieve the company's objectives.

All enterprises, whether service or manufacturing, financial or technical, retail or logistics, professional practice or supply chain, have constraints and budgets in terms of financial capital. The successful companies of the world have optimised their financial control. If financial flow and control is lacking, an enterprise will cease to exist. So the question is, "Is there a recipe that will work for all?" The answer is "No". Each company has a different environment and set of circumstances, and control measures should fit these circumstances.

Low throughput in a technical service company can be due to several factors - e.g. training, installed base, logistics, service agents, and many more. Overall profitability can be negatively affected if these factors are not properly addressed. How should throughput be maintained in a service company? This project investigated the problem of throughput in a service type organisation by using simulation modeling. The results could be used to improve personnel capacity planning and operational planning, and ultimately produce higher throughput and profit for the organisation.

\section{LITERATURE}

\subsection{Service organisations}

Blumberg [1] provides a comprehensive overview of how to use the service organisation as a profit centre. He provides valuable insights into the strategic view of service organisations or service departments within a larger organisation. Various facets of services are covered, such as marketing, pricing, and managing service elements. Blumberg provides a service-oriented economic model of how to control customer retention, and also discusses general service objectives in terms of the strategic objectives of the organisation.

Ptak and Schragenheim [2] provide an informative overview of field service provided by organisations. This type of service originates from the organisation that supplies technically advanced equipment that must be supported after being sold. The literature explains the very important function that this type of service delivery model has in the larger organisation, and highlights the future sales and current customer retention impact of this service.

Gilbert and Parhizgari [3] investigated the organisational effectiveness indicators that support service quality. The main aim of the paper was to offer a system to measure the service quality delivered by an organisation. The study that was done to extract the performance indicators involved some 8,924 employees of more than 100 
companies. The conclusion of the paper lists nine factors that can be measured to indicate whether quality service delivery will be achieved. The conclusion is that quality service can only be achieved if the employees delivering the service are competent and satisfied in their general working environment.

Lovelock [4] explains the concept of customer service and all the factors to be taken into account when performing the service. The service act and the various industries associated with it are investigated thoroughly. Also covered, in conjunction with the service act, is the concept of the service delivery system, and how the perception of the customer changes when the attributes of the delivery system change. Of particular interest is Lovelock's discussion of how the service organisation can build customer relationships and retain customers. Managing the demand from the market in terms of the service delivered is of great importance, and is discussed in detail.

\subsection{Simulation}

Albright et al [5] provide a chapter on simulation models. The importance of the variation of output to various inputs in the organisational environment is discussed, highlighting sensitivity analysis. A global perspective on simulation is discussed, and a real-life example is discussed where simulation was used to obtain useful results. The random generation of numbers in the MS Excel suite to be used in simulation is illustrated, and the lookup tables and special formulae are discussed. The typical news vendor problem is done using a spreadsheet simulation. Other probability distributions are also simulated. Finally, a more powerful add-in, @RISK, is discussed.

Law and Kelton [6] overhaul the simulation process from start to finish. This is a very comprehensive treatment of simulation, and covers all facets of simulation modeling and analysis. Of particular interest is the section on the credibility of simulation models, which includes the steps of validating and verifying simulation models. Input probability distributions and output monitoring is also covered extensively, and all the different distribution types used in simulation are explained.

Mjema [7] discusses the analysis of personnel capacity requirements in the maintenance department by using a simulation method. The paper focuses on increasing throughput in a maintenance department by using the SIMPLE++ simulation software package. Appropriate staff complement is the main focus, and this is achieved by implementing cross-functionality of staff. Uncertain variables that are unique to such an environment are examined, and these variables are incorporated into the various simulation runs.

Christer and Al-Zubaidi [8] present a study on the determination of the appropriate manpower requirements in the maintenance department of a modern hospital (the Withington Hospital in Manchester, England). Utilizing the terminating theory of simulation presented by Law and Kelton [6], they simulate various policies under consideration by management, and present the input-transformation-output simulation by using Extended Control and Simulation Language (ECSLPLUS). The model also incorporates sickness and holidays, and takes into account all types of 
maintenance jobs occurring in the hospital - i.e. electrical, mechanical, plumbing, and joinery. A discussion of the results addresses the critical number of maintenance staff versus the actual number of maintenance staff.

Duffuaa et al [9] provide valuable insight into the field of maintenance systems. They list all the activities performed by a typical maintenance department, and concede that simulation modeling in this area of study is lacking. The main features of a maintenance system are discussed, and the maintenance process is graphically depicted. They then build a generic conceptual model for maintenance systems as the first phase in the construction of a simulation model. They demonstrate the application of the conceptual model by using modules, and an explanation of each module is provided.

\section{RESEARCH METHODOLOGY}

This paper investigates one aspect of the control that a business needs in order for it to be more profitable and operationally efficient. Streamlining business in an efficient way is commonly known as operations research. This field of management science began during World War II, but has evolved significantly over the last ten years as a powerful way for organisations to control overhead costs, thus increasing the profitable revenue stream.

There are many innovative procedures, calculations, and methodologies that come under the operations research umbrella. These include linear and non-linear programming, application of the theory of constraints, analytical modeling, and simulation modeling. This paper will focus on simulation and simulation modeling. This technique was investigated for a business in the service environment, in order to provide factual data to support the decisions that have to be taken by management to steer the business in a profitable direction.

\section{THE SERVICE ORGANISATION}

In order to perform meaningful simulations of a system, it is first necessary to build a conceptual model of the system. The conceptual model consists of descriptions of the sub-systems under investigation in such a way that it can be translated into a computer program at a later stage. The advantage of first building the conceptual model is that all the relevant variables in the simulation, environmental factors, and important outputs, can be logically structured in a conceptual framework. This will aid in the correct formulation of the simulation model that is to be processed by the computer software.

\subsection{The simulated service organisation}

The service organisation that was used for the simulation case study is a global organisation specialising in the manufacture of highly sophisticated medical imaging equipment. The cost of the equipment to the end users, usually radiologists, runs into a few million dollars per system. The technical complexity of the systems requires highly trained engineers or technicians to perform maintenance tasks on the systems. 
The maintenance functions of the service department of the company are the focus of the simulation case study. The maintenance function involves various tasks, e.g. installation, commissioning, repair following breakdown, preventive maintenance, upgrades, and modifications.

Of these tasks, breakdowns in the systems are the most important. Breakdowns usually occur at random intervals, causing a loss of income to the customer through system downtime. When downtime occurs, patients cannot be scanned, operators (radiographers) are idle, and the radiologists (owners) cannot obtain throughput. If there are not enough technicians to perform the maintenance tasks, maintenance jobs will spill over and much overtime will be incurred by the technicians. If there are too many technicians, the service level will be high, but the cost to the service company in salaries and other benefits will be higher than the revenue provided by the services of the technicians.

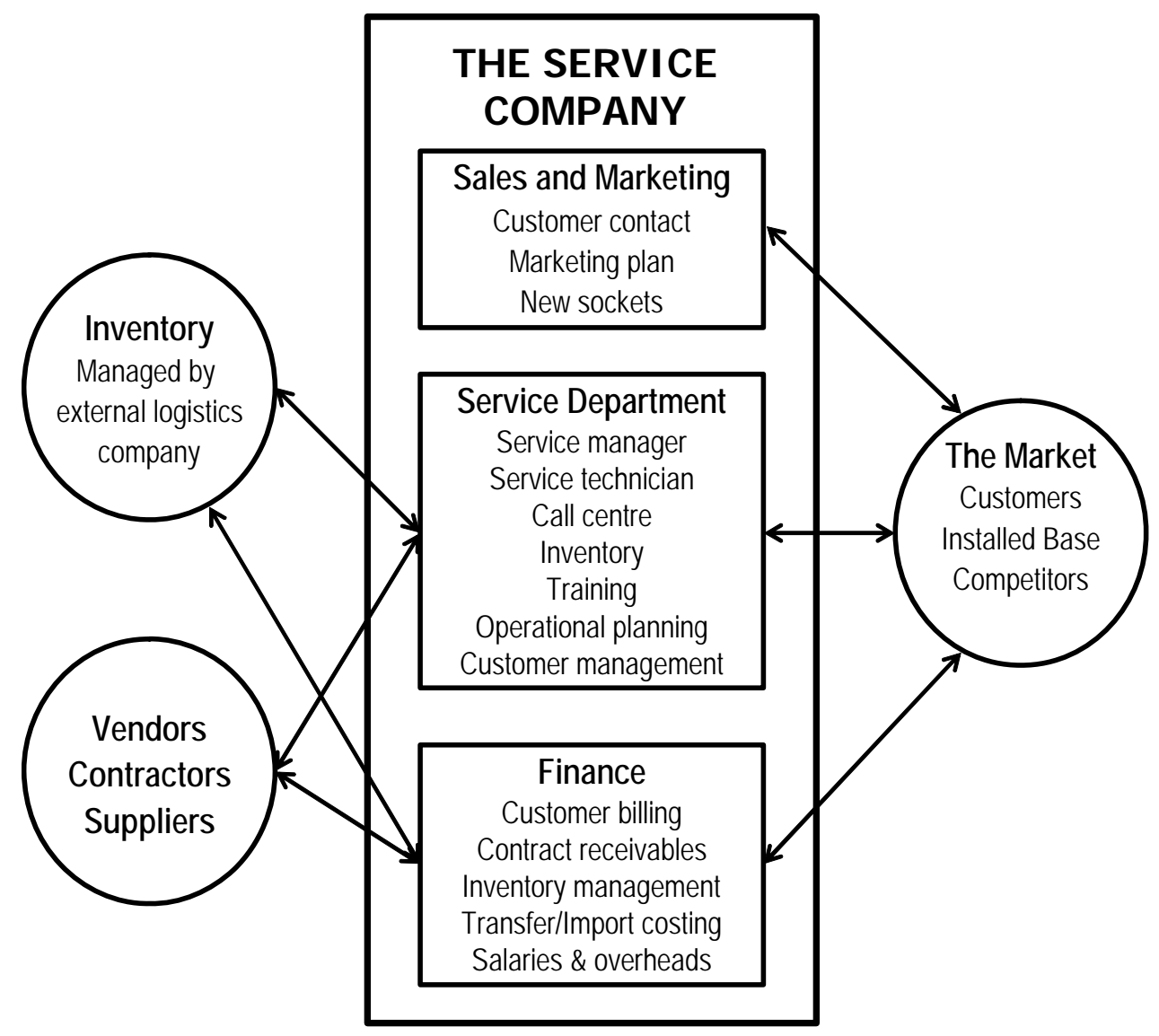

Figure 1: Conceptual view of the service company

\subsection{Conceptual model of the service company}

As mentioned earlier, it is of utmost importance first to understand the system that we are dealing with before attempting to do a simulation analysis of the system. The service company interacts with various external entities. At the very core of basic business, this is a matter of supply and demand: the market (customer) demands the 
supply of either a new system or technical service from the Service Department of the company. The function of Sales and Marketing is to promote the systems that the service company supplies, and to sell these systems into the new sockets. Alongside this, the financial division acts as a watchdog over all financial transactions. A conceptual model for the service company is presented in Figure 1.

\subsection{Characteristics of the maintenance system}

Maintenance activities are personnel-intensive, and the cost of maintenance personnel usually forms a large part of the total maintenance cost. An analysis of the personnel capacity requirement in the maintenance department could assist in determining the appropriate size of the maintenance department's staff, and thus reduce the cost of maintenance.

The key factor in the planning of personnel capacity in a maintenance or service environment is the time it takes to complete maintenance tasks. The task duration cannot be accurately predicted, but using historical data, probability distributions can be obtained and used in models for personnel capacity planning. Mjema [7] mentions the following factors that contribute to the uncertainty in personnel capacity planning:

- Maintenance work demand; arrival of jobs; job content; time to complete

- $\quad$ Service company characteristics, e.g. variability in demand

- Numerous factors affecting maintenance that make the analysis complex

\subsection{Service process flow}

The process flow for a typical call-out of a service company technician is indicated in Figure 2. The process starts with a complaint from a customer, or reporting a problem. If a technician is available he is assigned to the job; otherwise the job has to wait for the next technician to become available. Usually the technician is only able to determine the need for spare parts once he arrives on site and attends to the problem. If a required spare is not carried by the technician the job has to be interrupted until a spare has been acquired from head office. The job is closed when the technician has tested the system.

\subsection{Service company costs versus revenues}

The service company needs to balance customer satisfaction and overtime labor with cost and profits to the company. The revenue generated by the service company comes not only from services delivered by the technicians, but also from sales. With every new system sold, a one-year warranty is included. In this warranty period any breakdowns and resulting replacement of parts are not chargeable to the customer. To compensate for such events, a buffer amount is built into the sales price to cover the costs incurred by the service department in the warranty period. 

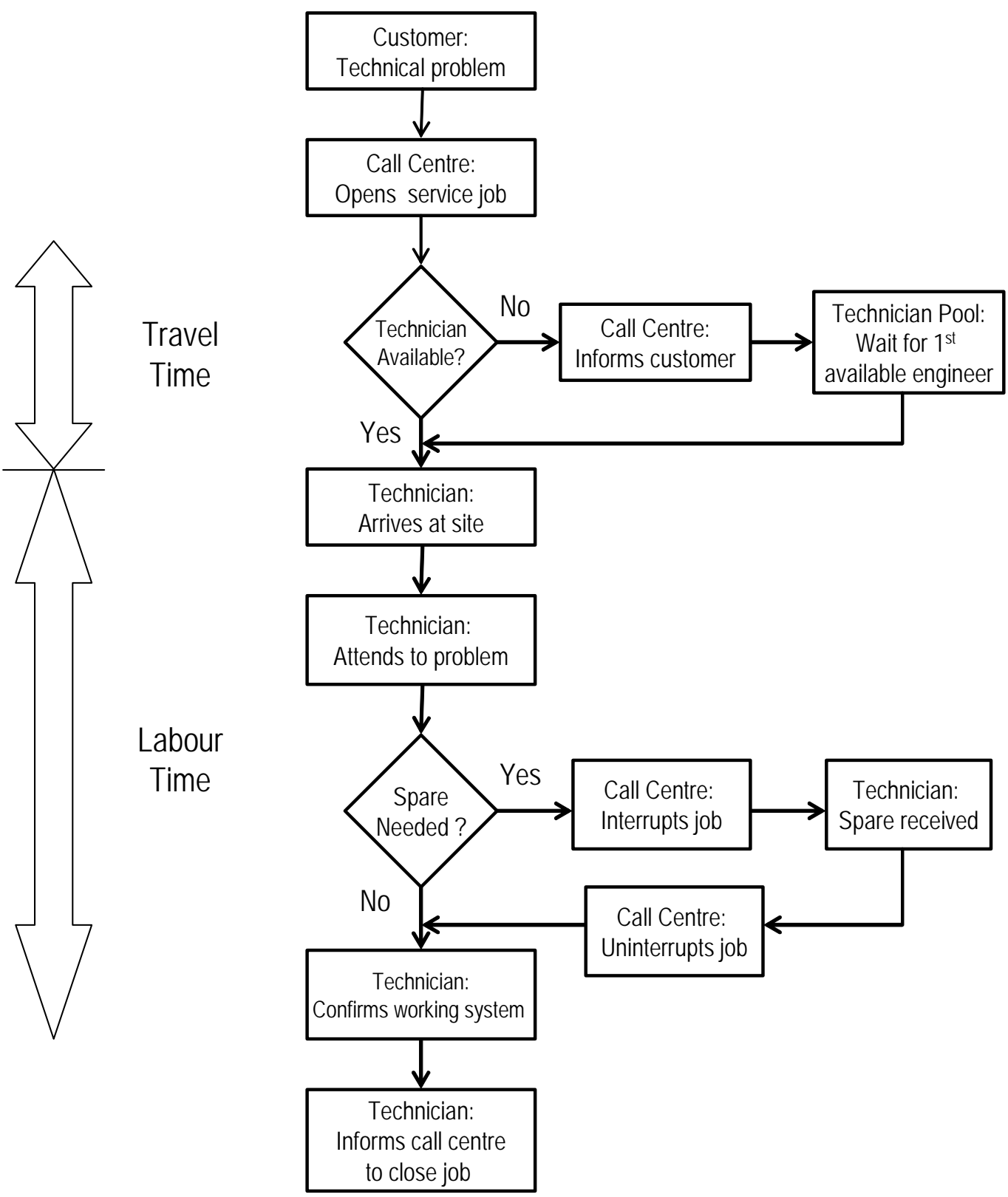

Figure 2: Model for service process flow

Additional revenue to the company comes from sales of accessories, and upgrades to the systems. Another major factor in the generation of the service department revenue is the consumption of spare parts by the systems. Real profit is only made from systems that are out of warranty and that are not operated under a service contract.

To avoid the risk of low revenue for the company through too few hourly-billed tasks per month, the emphasis is on the negotiation of service contracts for the systems. These contracts cover all service costs, including parts. Service contracts have advantages and disadvantages, the most obvious being revenue upfront, and the risk of extraordinary high cost jobs, respectively. 


\section{CHARACTERISTICS OF SIMULATION}

Simulation is defined by Winston [10] as "a technique that imitates the operation of a real-world system as it evolves over time". For simulation to have any meaningfulness, the system that is to be simulated must be clearly understood. Proper understanding of the system will enable the modeler to interpret the results correctly, and make rational decisions pertaining to the results to the advantage of the organisation requiring the simulation. In modern business, the technique of simulation has become a focal point for making business decisions before action is taken. The decisions taken are based on the science entrenched in the simulation method.

In large and complex systems, it is often difficult to analyse the systems using analytical methods because of the often-stochastic nature of the business environment. In these cases running simulation models over time can provide useful output data to determine the optimal policy or action for the organisation to implement. A clearly-defined simulation model has the advantage of being easily understood by anyone who decides to use it. Analytical models invariably require a multitude of assumptions, whereas simulation is a simpler approach that can deliver clear results. These results can then be analysed statistically, to the ultimate benefit of the organisation. Simulation also lends itself to flexibility: the modeler can choose different policies to be used in the simulation. In essence this can be equated to sensitivity analysis of analytical models. The basic simulation system is illustrated in Figure 3.

Stochastic simulation implies the sampling of stochastic variables from their different distributions. It is worth noting that not all the inputs to the simulation model are of a stochastic nature, but that at least one of the inputs must be of a defined distribution type. Other inputs to provide sense to the simulation can include static integers used to calculate outputs.

A number of simulation methodologies are available to study different types of systems. Monte Carlo Simulation (MCS) is typically used to study stochastic systems (some system variables are random) that are static - i.e. evolution of the system over time is not important. Discrete Event Simulation (DES) is typically used to study stochastic systems that are dynamic (where evolution over time is important) and where changes of system states occur at discrete time instances. Monte Carlo Simulation was chosen to study the service company, since it is simpler to use and the purpose of the simulation was to obtain certain output variables like the distribution of technician time over a one-day period. If the dynamics of the service company need to be studied and all machines to be serviced and repaired are included, Discrete Event Simulation should rather be used.

The Monte Carlo Simulation technique involves the generation of input variables by using a random number generator. This generator will provide the input variable in accordance with its real-life probability distribution, enabling the simulation to provide the most accurate solution for the system under scrutiny. 


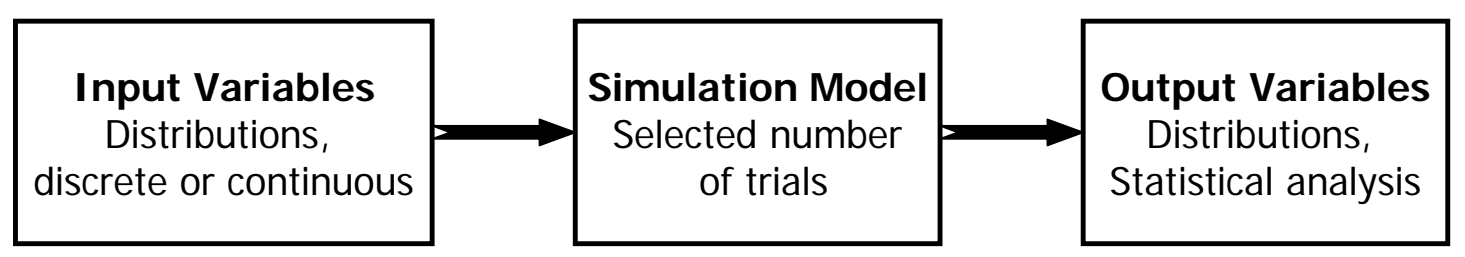

Figure 3: The basic simulation system and process

Figure 3 refers to the simulation process in terms of the number of trials or runs selected. Any number of trials can be selected; the modeler can determine this number. A small number of trials (e.g. 50) will not provide a good answer: 1,000 to 2,000 trials are usually used to provide more consistent results. The number of trials depends on the type of software used, the degree of accuracy needed, and the importance of achieving 'close to real life' solutions, the processing speed of the computer performing the simulation, the number of prescribed policies, etc.

The outputs illustrated in Figure 3 refer to the results, individually or collectively, obtained from the stochastic input(s) and the process of calculation using each individual input and associated calculation factors. The outputs will have a distribution of their own, owing to the input distributions. From these outputs, statistical analyses can be made to provide insight into rational decision-making.

\section{THE SIMULATION MODEL}

\subsection{Conceptual model for simulation}

One of the key benefits of simulation methodology is that it allows a company to see how important outputs respond to various scenarios. Each scenario, which is determined by certain inputs and operating policies, can be simulated, and statistics can be collected. By running enough scenarios, the company obtains useful information about which inputs and policies tend to produce the best outputs.

A simulation model is a computer model that imitates a real-life situation. It is like other mathematical models, but it explicitly incorporates the uncertainty of one or more input variables by using that variable's probability distribution as input to the model. When the simulation is run using the values that the input variables take on, a record is kept of the subsequent output that is of value for the company. In this way the variation of the output as the input varies can be followed.

The numeric modeling technique of simulation studies the effect of a system's transfer function on the inputs to the system by generating applicable outputs. By running such a simulation many times for a particular set of inputs, the expected value produced by the transfer function can be determined, as well as its distribution. By changing the values assigned to the inputs, the effect on the outputs can be modeled. By using probability distributions as the inputs, the transfer function of the system will produce probability distributions of the output. A conceptual model for the simulation system is shown in Figure 4. 


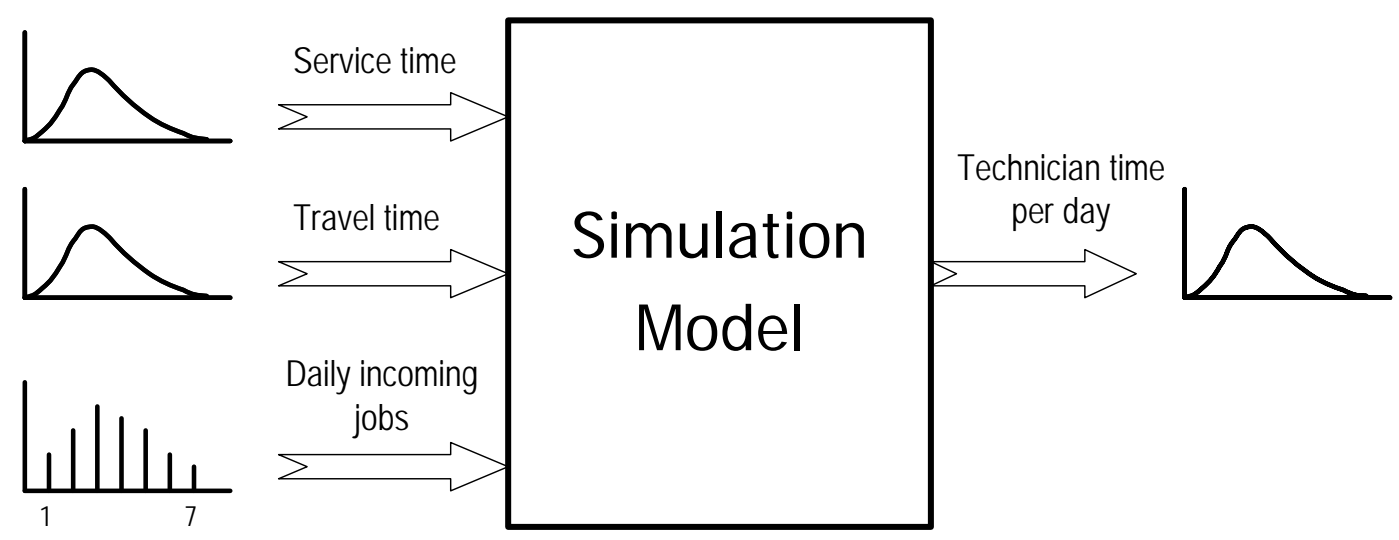

Figure 4: Conceptual simulation system model for the service company

The inputs to the simulation model are the job time distribution, travel time distribution, and number and type of daily incoming jobs. The main output of the simulation is the distribution of technician time required per day. Other outputs are the chargeable time and the time that must be supplemented by contracts. The distribution of technician time per day provides valuable insight into the variation of this output variable and the expected value.

\subsection{Input and output simulation variables}

The next step in the simulation approach is to collect the relevant data and to construct a conceptual model that the simulation can be based upon. The data collected has to be substantial enough to provide a 'real as possible' simulation that adds value to the decision-makers using the simulation outputs. For this reason, the modeler in this case has decided to take the necessary data from the service company database for the last five years. This historical data should be sufficient to provide a true reflection of future scenarios that the service department might face.

\subsection{Input variables}

There are four stochastic input variables. A brief discussion of each is provided.

Input Variable \#1: Service job time

This is the most important and crucial variable to evaluate in order for capacity planning to be effective. The data obtained has been manipulated by means of the MS Excel formulae to provide a complete time for each of the jobs (about 4,500) in the last five years. It is important to realise that every product line will have a different job time distribution owing to differences in the systems. For the purposes of the development of this model, however, the modeler has selected a specific product line of the service company, and analysed the historical data for the product.

Once the job times have been obtained from the MS Excel spreadsheet, it is a simple matter of fitting the data to obtain a probability distribution of the data. The Bestfit add-in for Microsoft Excel is part of the Decision Tools software package from the 
Palisade Company. This software was used to obtain the best fit for the service and travel historic data. A lognormal distribution provided the best fit for the product line selected.

Input Variable \#2: Service job travel time

Owing to the size of the systems that need to be maintained, all service jobs are performed on the premises of the customer. This requires travel time, and costs are incurred by both parties. In an attempt to keep standard costing, the service company charges customers according to travel zones based on the radius of customer distance from the head office.

Input Variable \#3: Number of incoming jobs per day

This variable is created by various factors that are difficult to quantify, e.g.

- The total installed base of systems in the field (more systems mean more incoming jobs)

- Age of the systems in the field (older systems generally require more maintenance)

- Reliability of the systems in the field in terms of design and manufacturing

- Experience and knowledge of the service technicians (experience can reduce callbacks)

- Service contracts (customers with service contracts generally demand more attention)

Input Variable \#4: Service contract/No service contract

This variable significantly determines the revenue generated by the job. Every incoming job can be either a contract or no-contract customer, and it can be simulated in real time. In the service company about $70 \%$ of cutomers have contracts, $30 \%$ do not. This ratio was kept constant in all simulations of the case study.

\subsection{Output variables}

A number of output variables are relevant. The three main output variables are discussed briefly.

\section{Output Variable \#1: Total technician time needed per day}

This is the main aim of the simulation. With the time needed each day known, the Service Manager can establish whether or not the current pool of service technicians is adequate. The simulation program will use all the input variables and their respective distributions to simulate normal service call operations. At this point, we are only concerned with stochastic maintenance calls. (The various other functions that the service technicians perform can be added to the model at a later stage.) This will keep the proposed model generic, allowing its use by any other service support 
organisation having a different structure and operations from the service company.

\section{Output Variable \#2: Total chargeable time per day}

This variable is directly related to service contracts. As jobs come into the call centre and are allocated to the service technicians, they are also tagged as being a contract customer or not. Service contract customers are not chargeable on an hourly basis, and vice versa. In calculating the technician time needed (variable \#1), it is possible to calculate the revenue that the service company can expect per day for the relevant product line. This output variable splits the revenue into labour and travel charge.

\section{Output Variable \#3: Total contract time (non-chargeable) time for the day}

This variable is included to highlight the gap left by hourly-billed service jobs. This gap needs to be filled with the revenue from service contracts in order to cover the overheads of the employed technician base. The time that a technician spends on contract jobs should be included in the simulation even though it is not generating extra revenue.

\section{RESULTS OF ANALYSIS}

\subsection{Introduction}

The full effect of simulation theory can only be realised with a well-constructed simulation model and a number of simulation runs. Various useful statistical data can be calculated using simulation software, which will enable management to observe trends and to study the outputs for changes to the inputs. Typical 'what if' questions can be answered, and a sensitivity analysis can be performed on the input variables.

One simulation run provides data for one day of service company operation. If 10,000 runs or trials are performed, the model represents 10,000 days of operation. From this number of simulation runs, a good average of technician time needed per day can be obtained, and this output can be used to decide on the optimum number of personnel needed to provide the service.

The outputs derived from the simulation are the chargeable and non-chargeable time distributions over the 10,000 days. This output has been incorporated into the model to indicate the financial status of the service department in terms of cost to the company of the technicians vs. the incoming revenue from the applied time. Thus, in deciding the correct number of technicians, there is a definite trade-off: customer satisfaction vs. company overhead.

The service company used in the case study has five product lines, and each product line has dedicated technicians allocated to it. The computer simulation model was developed for one product line only, but can easily be extended to include all five. 


\subsection{Assumptions for simulation}

All analytical models involve a number of assumptions. The following were made in this case study.

- Only breakdown jobs are taken into account

- There are no overtime considerations

- Normal leave and sick leave of the technicians is not taken into account

- A minimum of nil jobs and a maximum of five jobs is received each day

- Training time of the technicians is not considered

\subsection{Output of simulation runs}

The @RISK simulation add-in for MS Excel was used, but various other simulation software packages are available to perform this simulation. A snapshot of the simulation runs is shown in Table 1, giving an indication of the output that was generated for each simulated day of operation.

\begin{tabular}{|c|r|r|r|r|r|}
\hline $\begin{array}{c}\text { Iteration } \\
\text { number }\end{array}$ & $\begin{array}{c}\text { Total time } \\
\text { (hours) }\end{array}$ & $\begin{array}{c}\text { Labor (h) } \\
\text { (Chargeable) }\end{array}$ & $\begin{array}{c}\text { Travel (h) } \\
\text { (Chargeable) }\end{array}$ & $\begin{array}{c}\text { Labour (h) } \\
\text { (Contracts) }\end{array}$ & $\begin{array}{c}\text { Travel (h) } \\
\text { (Contracts) }\end{array}$ \\
\hline $\mathbf{1}$ & 4.25 & 2.25 & 2.00 & 0.00 & 0.00 \\
\hline $\mathbf{2}$ & 14.00 & 11.75 & 2.25 & 0.00 & 0.00 \\
\hline $\mathbf{3}$ & 16.50 & 12.50 & 1.00 & 1.25 & 1.75 \\
\hline $\mathbf{4}$ & 13.00 & 5.75 & 1.50 & 3.50 & 2.25 \\
\hline $\mathbf{5}$ & 7.00 & 0.00 & 0.00 & 2.50 & 4.50 \\
\hline $\mathbf{9 9 9 6}$ & & Simulation runs 6 to & 9995 & & \\
\hline $\mathbf{9 9 9 7}$ & 2.50 & 4.00 & 2.50 & 2.00 & 0.00 \\
\hline $\mathbf{9 9 9 8}$ & 3.50 & 1.25 & 0.75 & 0.00 & 0.00 \\
\hline $\mathbf{9 9 9 9}$ & 27.25 & 0.00 & 0.00 & 2.75 & 0.75 \\
\hline $\mathbf{1 0 0 0 0}$ & 11.75 & 7.00 & 4.25 & 13.75 & 2.25 \\
\hline
\end{tabular}

Table 1: Snapshot of output of simulation runs

\subsection{Summary of simulation outputs}

The mean values for a number of output variables, as well as standard deviation for the total technician time, are summarised in Table 2. The results were calculated from a simulation involving 10,000 trials (or runs). 


\begin{tabular}{|l|l|}
\hline Simulation Output Variable & Value \\
\hline Mean total technician time needed per day (h) & 7,9 \\
\hline Standard deviation of total technician time (h) & 7,6 \\
\hline Mean chargeable labour time per day (h) & 2,22 \\
\hline Mean chargeable labour income per day (R) & 1332 \\
\hline Mean chargeable travel time per day (h) & 0,68 \\
\hline Mean chargeable travel income per day (R) & 272 \\
\hline Mean total income per day (Rand) & 1604 \\
\hline Average number of jobs received per day & 1,7 \\
\hline Probability for 4 or less jobs per day (\%) & 95,0 \\
\hline Total time per day at 95\% probability (h) & 22,5 \\
\hline
\end{tabular}

Table 2: Summary values from simulation

\subsection{Graphical output of simulations}

A typical output distribution for total technician time per day (service plus travel time) is indicated in Figure 5 for a simulation involving 10,000 trials.

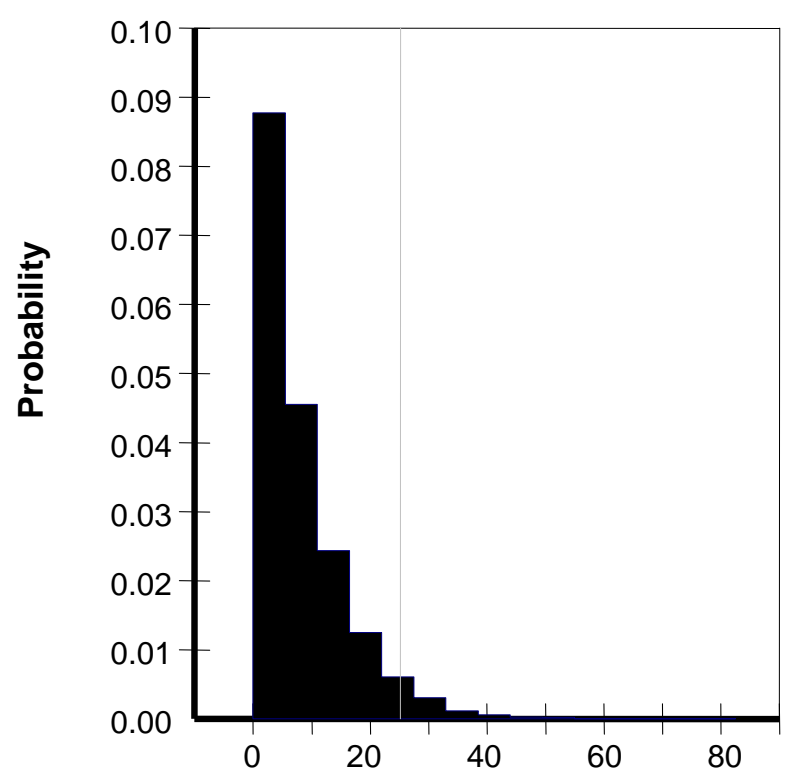

Total technician time per day (h)

Figure 5: Distribution of total technician time per day

The mean time for this simulation in Figure 5 was 8,2 hours, compared with 7,9 
hours for the simulation reported in Table 2. From Figure 5 it is clear that the total time distribution is quite sharp and skewed to the right. This is what might be expected, since the actual total time per day is hardly ever less than eight hours. The $95 \%$ percentile of the total time output distribution is about 23 hours, indicating that there is a $95 \%$ probability that the total time required per day will be less than 23 hours.

\subsection{Sensitivity analysis}

A sensitivity analysis can indicate which input parameter has the largest influence on the output parameters. This influence can be the result of changing values of input parameters, changing input parameter probability distributions, or changing the level of detail of a subsystem. In the system of the service company that we are dealing with, the most likely events to change the technician time needed per day are:

- Installed base (number of systems). With an increase of systems in the field, there will be an increase of incoming jobs, hence a probability distribution change for this input variable

- Installed base age and reliability of installed base (older systems exhibit more failures)

- Technician experience and knowledge (experienced technicians can perform tasks quicker and in more consistently)

- More contracts sold will increase the number of planned maintenance jobs (an optional input to our model)

- More systems sold in the market will increase installation time needed, and also warranty time repairs and service

- Labour and travel charges will impact on the revenue generated through the chargeable labour and travel charges per day

For most of these factors, the computer simulation model will have to be modified in order to reflect the additional inputs.

\subsection{Decision on the number of technicians}

To achieve overall customer satisfaction, every incoming breakdown job on any given day needs to be completed within that day. In order for this scenario to be sustained, service technician resources need to be available to satisfy the objectives. From the results of the simulation runs, it is seen that an average of about eight hours per day is needed to complete the incoming jobs, and this value includes the labour and travel time. Each technician in the employ of the service company can effectively complete eight hours of work per day. Three feasible options for service technicians are discussed briefly.

\section{Option 1: Employ only one technician}

This option is risky since the standard deviation of the total time needed per day is about 7,6 hours (see Table 2). Choosing this option could have a disastrous effect on customer satisfaction. Many jobs would not be completed during normal hours, and 
the technician would have to work overtime on many days. Customers would not be satisfied with the response time and service provided.

\section{Option 2: Employ two technicians}

This option will effectively provide 16 hours per day. When taking the mean technician time needed per day $(7,9 \mathrm{~h})$ as well as the standard deviation $(7,6 \mathrm{~h})$ into account, this seems to be a feasible solution. Other factors, such as those stated in the assumptions, need to be considered, and a buffer needs to be built into the employment complement. These include the optional inputs into the model, i.e. installations, planned maintenance, and field modifications. Other considerations relate to the conditions of employment: leave, sickness, and overseas training. The simulation could be improved by including some of these factors, and would probably be necessary to make an informed decision.

\section{Option 3: Employ three technicians}

This option will effectively provide 24 hours. This seems to be the best option: an adequate buffer is maintained, and more importantly, the worst-case scenario is catered for. From the simulation runs it is noted that the $95^{\text {th }}$ percentile is approximately 23 hours.

A final decision on the number of technicians to employ will involve a calculation and comparison of the monthly profit for each scenario.

\section{CONCLUSIONS}

The results obtained through the simulation model can be used to arrive logically at the best personnel employment strategy for the service company. Once this point had been reached, further analysis identified the business model that yielded the optimum profit for the service company. For the simplified model discussed in this paper it appears that three technicians would satisfy the company's service level objective.

Throughout the analysis it is important to keep the customer in mind. Profit to the company can increase dramatically if the number of technicians is decreased, but this will directly affect service to the customers. All the important factors mentioned earlier regarding downtime of systems and the impact this has on the customer and on the service company have to be kept in mind.

Management can use the simulation model to perform various scenario studies. These scenarios can include varying the contract/no-contract split, cross-training technicians, and employing fewer or more technicians. The model can also be used in the company's service department budget planning.

\section{REFERENCES}

[1] Blumberg, D.F. 1991. Managing service as a strategic profit center, McGraw-Hill, New York. 
[2] Ptak, C.A. and Schragenheim, E. 2000. ERP: Tools, techniques, and applications for integrating the supply chain, The St Lucie Press, New York.

[3] Gilbert, R.G. and Parhizgari, A.M. 2000. Organizational effectiveness indicators to support service quality, Managing Service Quality, 10 (1), pp 4651.

[4] Lovelock, C.H. 2001. Services marketing: People, technology, strategy, $4^{\text {th }}$ edition, Prentice Hall, New Jersey.

[5] Albright, S.C., Winston, W.L. and Zappe, F. 1999. Data analysis and decision making with Microsoft Excel, Brooks Cole.

[6] Law, A.M. and Kelton, D.W. 1991. Simulation modeling and analysis, McGraw-Hill Inc., New York.

[7] Mjema, E.A.M. 2002. An analysis of personnel capacity requirement in the maintenance department by using a simulation method, Journal of Quality in Maintenance Engineering, 8 (3), pp 253-273.

[8] Christer, A.H. and Al-Zubaidi, H. 1997. Maintenance manpower modeling for a hospital building complex, European Journal of Operations Research, 99, pp 603-618.

[9] Duffuaa, S.O., Ben-Daya, M., Al-Sultan, K.S. and Andijani, A.A., 2001, A generic conceptual simulation model for maintenance systems, Journal of Quality in Maintenance Engineering, 7 (3), pp 207-219.

[10] Winston, W.L. 1994. Operations research: Applications and algorithms, $3^{\text {rd }}$ edition, Duxberry Press, California. 